\title{
Imiquimod inhibits the growth of SGC-7901 cells in vitro through induction of autophagy and apoptosis
}

\author{
JIONG JIANG, LEI DONG, HAI-TAO SHI, XIAO-YAN GUO, BIN QIN, YAN WANG and HONG LI \\ Department of Gastroenterology, The Second Affiliated Hospital of Xi'an Jiaotong University, \\ Xi'an, Shaanxi 710003, P.R. China
}

Received December 24, 2014; Accepted September 24, 2015

DOI: $10.3892 / \mathrm{mmr} .2015 .4524$

\begin{abstract}
Imiquimod, the most prominent Toll-like receptor 7 agonist, has direct anti-tumor activity and can induce autophagy and apoptosis in various types of human cancer. The aim of the present study was to examine the anti-tumor effects of imiquimod and their underlying mechanisms in SGC-7901 cells. Imiquimod exerted an inhibitory effect on cell proliferation in a dose- and time-dependent manner as indicated by an MTT assay. Imiquimod induced autophagy as well as apoptosis, while simultaneous treatment with 3-methyladenine (3-MA), an autophagy inhibitor, decreased the toxicity of imiquimod. Furthermore, blocking of autophagy by 3-MA exerted an inhibitory effect on imiquimod-induced apoptosis, which indicated that autophagy can function as a mechanism which, upon activation, directly leads to apoptosis and cell death of SGC-7901 cells. The results of the present study suggested that imiquimod has potent direct activity against gastric cancer cells by inducing autophagy and apoptosis.
\end{abstract}

\section{Introduction}

Toll-like receptors (TLRs) were first characterized as being able to recognize various pathogen-associated molecular patterns and forming part of the first line of defense against pathogens (1). Furthermore, TLRs were shown to have a broad range of biological activities, as they are involved in immune regulation, tissue repair and have anti-viral and anti-neoplastic effects. TLR ligands have been considered as potential targets for the development of therapeutic drugs for infectious diseases, autoimmune diseases and cancer (2,3). 1-[2-methylpropyl]-1H -imidazo[4,5-c]quinolin-4-amine) (imiquimod) is a synthetic agonist of TLR7 that has been used as topical therapeutic for certain skin neoplasms such as basal cell carcinoma (4).

Correspondence to: Dr Lei Dong, Department of Gastroenterology, The Second Affiliated Hospital of Xi'an Jiaotong University, 157 Xi'wu Road, Xi'an, Shaanxi 710003, P.R. China

E-mail: donglei556@yeah.net

Key words: Toll-like receptor 7, imiquimod, autophagy, SGC-7901, gastric cancer
Accumulating evidence indicated that the mechanism of action of imiquimod is not restricted to the elicitation of the innate and adaptive immune responses, but also directly induces autophagy or apoptosis in certain types of tumor cell (5-7).

Autophagy is a physiological process during which the cell's cytosol and organelles are sequestered within double-membrane vesicles termed autophagosomes, which are then fused with lysosomes for degradation and recycling of cytoplasmic constituents (8). Autophagy provides a survival advantage for the organism under multiple stresses, including starvation, oxygen deprivation and intoxication (9). However, if autophagy is overactivated and allowed to escalate, it eventually leads to cell death due to depletion of proteins important for the functioning of complex signaling pathways (10). Dysfunctional autophagy has been observed in numerous types of human cancers and increasing evidence suggested that the cytotoxicity of certain anti-tumor agents is based on the induction of autophagy or promotion of a non-apoptotic, autophagic cell death (11).

For the past few decades, gastric cancer mortality has decreased in most areas of the world due to the availability of screening for early detection and improved treatments (12); however, resistance to chemotherapy and tumor recurrence still make this disease the second leading cause of cancer-associated mortality worldwide (13). Therefore, novel and effective therapies for gastric cancer are in demand. Based on the previously demonstrated efficacy of imiquimod on colon cancer cells (5), the present study hypothesized that imiquimod may have suppressive effects against other gastrointestinal cancers, including gastric cancer.

To the best of our knowledge, no previous study has investigated whether imiquimod can decrease the viability of gastric cancer cells, and its mechanisms of its action have also remained elusive. Therefore, the present study assessed the anti-proliferative and cytotoxic effects of the TLR7 agonist imiquimod on a gastric cancer cell line and investigated the probable molecular mechanisms of its action.

\section{Materials and methods}

Cell culture and reagents. The human gastric cancer cell line SGC-7901 was obtained from the Cell Bank of the Chinese Academy of Sciences (Shanghai, China). Cells were maintained in RPMI-1640 medium containing $10 \%$ fetal bovine serum (both from Invitrogen; Thermo Fisher Scientific, Waltham, MA, 
USA) with $100 \mathrm{U} / \mathrm{ml}$ penicillin and $100 \mu \mathrm{g} / \mathrm{ml}$ streptomycin (both from Gibco; Thermo Fisher Scientific) at $37^{\circ} \mathrm{C}$ in a humidified incubator containing $5 \% \mathrm{CO}_{2}$. Prior to all incubations with imiquimod (Enzo Life Sciences, Farmingdale, NY, USA), cells were seeded into dishes and allowed to attach for $24 \mathrm{~h}$ to reach the logarithmic growth phase.

Cell viability assay. The effects of imiquimod on cell viability was evaluated in vitro using the 3-(4,5-dimethylthiazol-2-yl)-2,5-diphenyltetrazolium bromide (MTT; Sigma-Aldrich, St. Louis, MO, USA) assay. Cells were seeded in 96-well plates at $5 \times 10^{3}$ cells/well and then incubated with various doses of imiquimod $(25,50,100$ or $200 \mu \mathrm{g} / \mathrm{ml})$ for various time periods (12, 24, 48 and $72 \mathrm{~h})$. Subsequently, $20 \mu \mathrm{l}$ MTT solution $(5 \mathrm{mg} / \mathrm{ml})$ was added to each well and the plates were re-incubated at $37^{\circ} \mathrm{C}$ for $4 \mathrm{~h}$. The supernatant was carefully removed, formazan products were dissolved in $150 \mu \mathrm{l}$ dimethyl sulfoxide (Sigma-Aldrich) with agitation for $5 \mathrm{~min}$, and the absorbance was measured at $490 \mathrm{~nm}$ using a PowerWave XS microtiter plate reader (Bio-Tek, Winooski, VT, USA). The effects of autophagy regulators on cell viability were detected following 1-h pre-incubation with $5 \mathrm{mM} 3$-methyladenine (3-MA) followed by treatment with imiquimod for $24 \mathrm{~h}$.

Transmission electron microscopy. For electron microscopy, the SGC-7901 cells were treated with $100 \mu \mathrm{g} / \mathrm{ml}$ imiquimod for $12 \mathrm{~h}$, fixed in ice with cold glutaraldehyde (Wolsen, Xi'an, China; $2.5 \%$ solution in phosphate buffer) at $4^{\circ} \mathrm{C}$ for a minimum of $4 \mathrm{~h}$ and then fixed in $1 \%$ osmium tetroxide (Wolsen). Following dehydration in a graded ethanol series, samples were embedded in Agar 100 resin (Agar Scientific, Stansted, UK). Ultrathin sections were stained with uranyl acetate and lead citrate and analyzed by transmission electron microscopy (H-7650; Hitachi, Tokyo, Japan).

Monodansylcadaverine (MDC) staining. MDC, a specific marker of autophagic vacuoles, was employed to stain autophagosomes. $1 \times 10^{5}$ cells were seeded into a six-well plate and allowed to attach for $24 \mathrm{~h}$. The cells were treated with $100 \mu \mathrm{g} / \mathrm{ml}$ imiquimod for $12 \mathrm{~h}$ and then stained with $0.05 \mathrm{mM}$ MDC (Sigma-Aldrich) in fresh RPMI-1640 for $30 \mathrm{~min}$ at $37^{\circ} \mathrm{C}$ in the dark. After three washes with phosphate-buffered saline (PBS), the cells were harvested and rinsed with PBS. Intracellular MDC intensity was measured using a flow cytometer (BD Biosciences, Franklin Lakes, NJ, USA) at an excitation wavelength of $360 \mathrm{~nm}$.

Western blot analysis. Cells were seeded in six-well plates at a density of $1 \times 10^{5}$ cells/well and treated with imiquimod (0, 25,50 or $100 \mu \mathrm{g} / \mathrm{ml}$ for $0,6,8,12,24$ or $36 \mathrm{~h}$ ) with or without 3-MA (5 mM; Sigma-Aldrich). Following two washes with cold PBS, cells were lysed in radioimmunoprecipitation assay lysis buffer on ice for $1 \mathrm{~h}$. The lysates were centrifuged at $20,627 \times \mathrm{g}$ at $4^{\circ} \mathrm{C}$ for $20 \mathrm{~min}$ and the supernatant was collected. The protein concentration was measured using a bicinchoninic acid protein assay kit (Pierce ${ }^{\mathrm{TM}}$ BCA Protein Assay Reagent A; cat no. 23222; Thermo Fisher Scientific). Equal amounts of protein $(20-30 \mu \mathrm{g})$ were applied to the SDS-PAGE gel (12\% for Bcl-2, Bax, LC3 and cleaved caspase 3 and 10\% for beclin-1, cleaved caspase 9). After electrophoresis, the resolved proteins

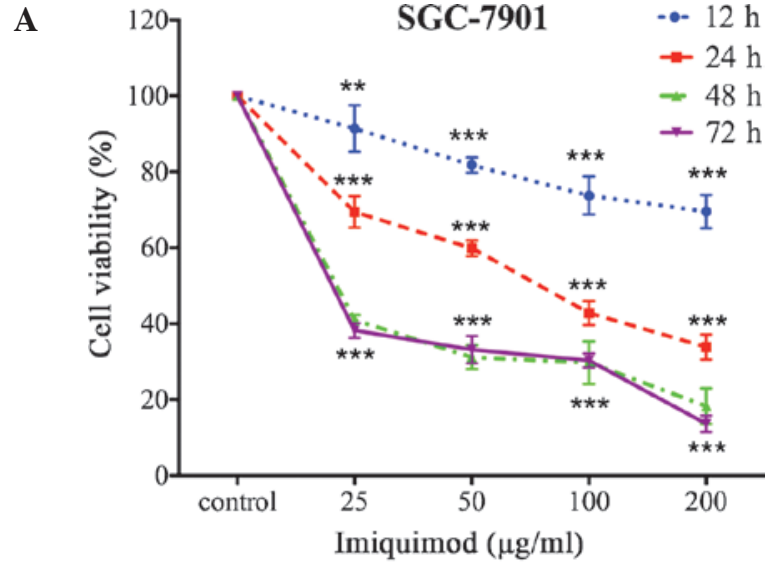

B

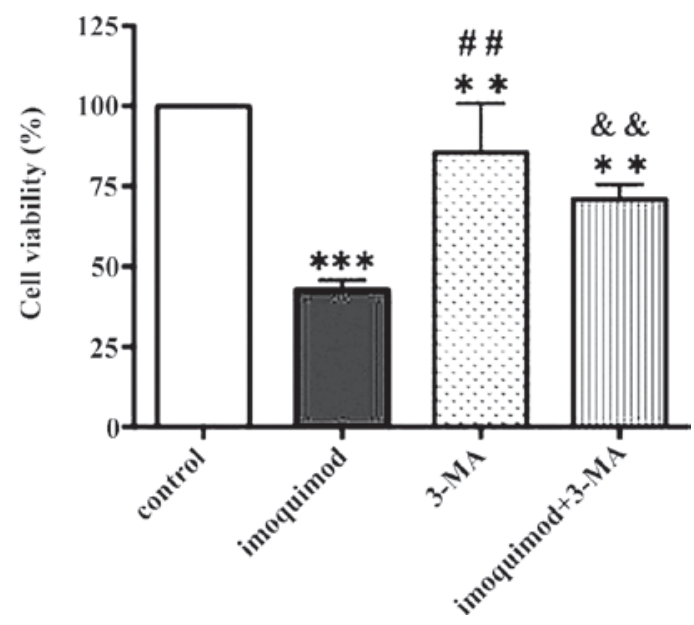

Figure 1. Anti-proliferative effects of imiquimod on the SGC-7901 cell line. (A) MTT assay revealed a dose- and time-dependent decrease in cell viability of imiquimod-treated SGC-7901 cells. (B) Blocking of autophagy with $5 \mathrm{mM} 3$-MA increased the cell viability following treatment with imoquimod $(100 \mu \mathrm{g} / \mathrm{ml})$ as indicated by an MTT assay. Values are expressed as the mean \pm standard deviation. ${ }^{* *} \mathrm{P}<0.01 ;{ }^{* * *} \mathrm{P}<0.001$ vs. control; ${ }^{\# \#} \mathrm{P}<0.01$, \&\& $\mathrm{P}<0.01$ vs. imiquimod-treated cells. MA, methyladenine.

were transferred to a polyvinylidene difluoride membrane (Wolsen). The membrane was blocked in Tris-buffered saline supplemented with $5 \%$ skimmed milk for $2 \mathrm{~h}$ and subsequently incubated with the following primary antibodies at $4^{\circ} \mathrm{C}$ overnight: Rabbit anti-beclin 1 monoclonal antibody (mAb; cat. no. 2026-1; 1:1,000 dilution; Epitomics, Burlingame, CA, USA), rabbit anti-light chain (LC)3 polyclonal antibody (pAb) (cat no. L7543; 1:500 dilution; Sigma-Aldrich), rabbit anti-B-cell lymphoma 2 (Bcl-2) pAb (cat. no. BS3711; 1:500 dilution; Bioworld Technology, Nanjing, China), rabbit anti-Bcl-2-associated X protein (Bax) pAb (cat. no. BS2538; 1:500 dilution; Bioworld Technology), rabbit anti-cleaved caspase-3 pAb (cat. no. 9661; 1:1,000 dilution; Cell Signaling Technology, Inc., Danvers, MA, USA), rabbit anti-cleaved caspase- 9 pAb (cat no. 9505; 1:1,000 dilution; Cell Signaling Technology, Inc.) or mouse anti-GAPDH mAb (cat. no. Sc-32233; 1:200 dilution; Santa Cruz Biotechnology, Inc.). Subsequently, membranes were incubated with the secondary anti-mouse and anti-rabbit antibodies (1:5,000 dilution; Bioworld Technology) for $2 \mathrm{~h}$ at $37^{\circ} \mathrm{C}$. GAPDH was used as the loading control. The specific protein expression levels were detected using an enhanced chemiluminescence kit (Western Blotting Luminol Reagent; 

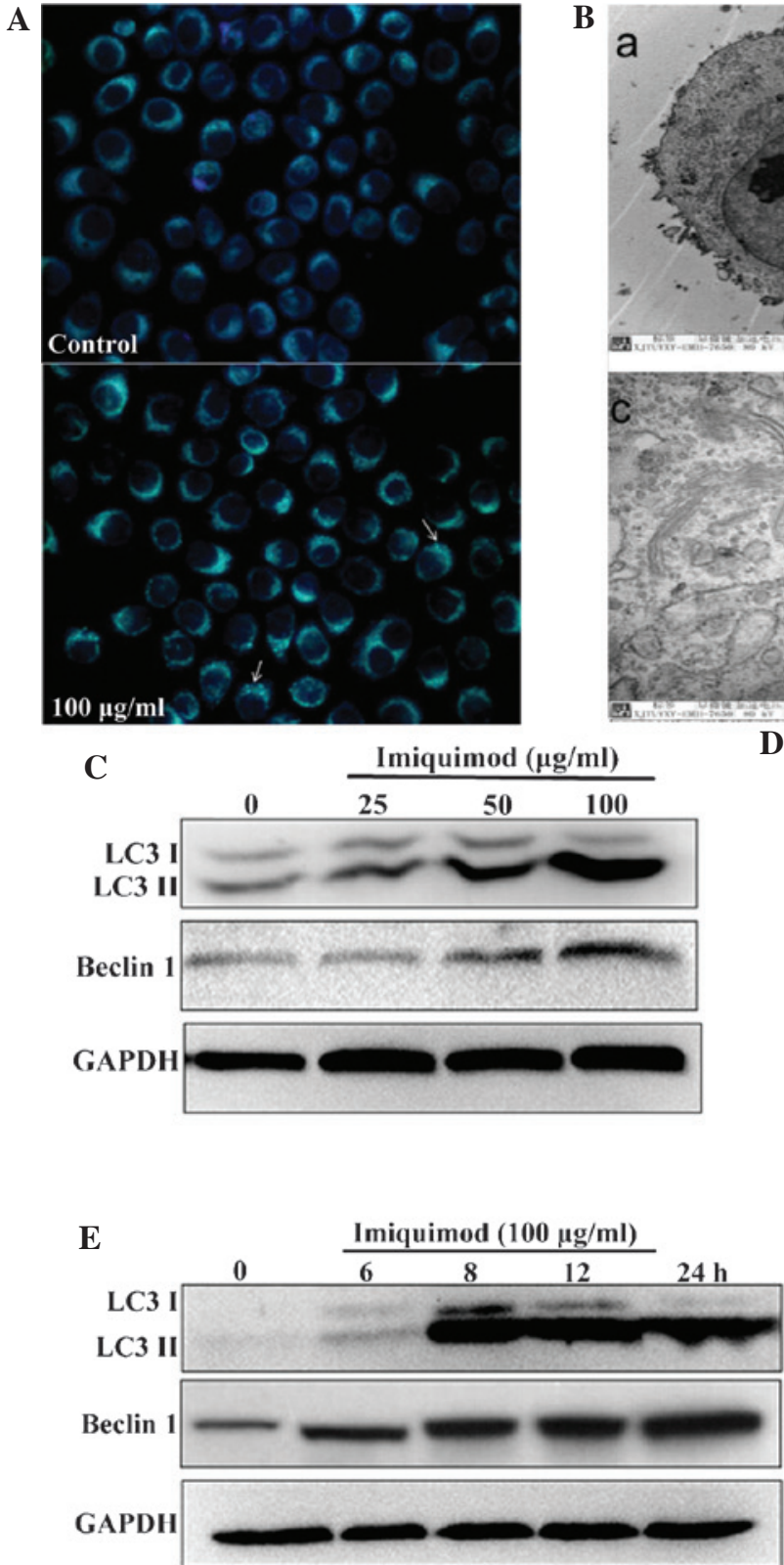

D
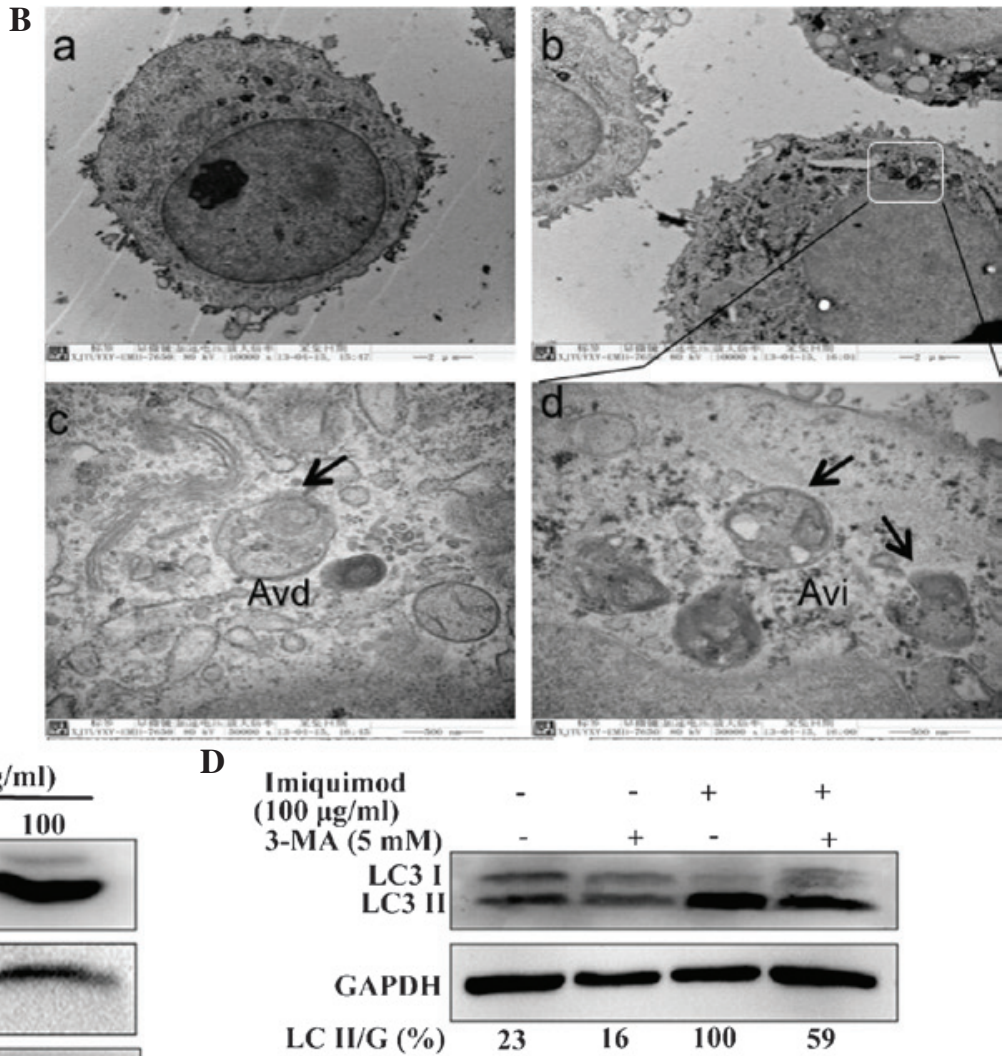

$\mathbf{F}$

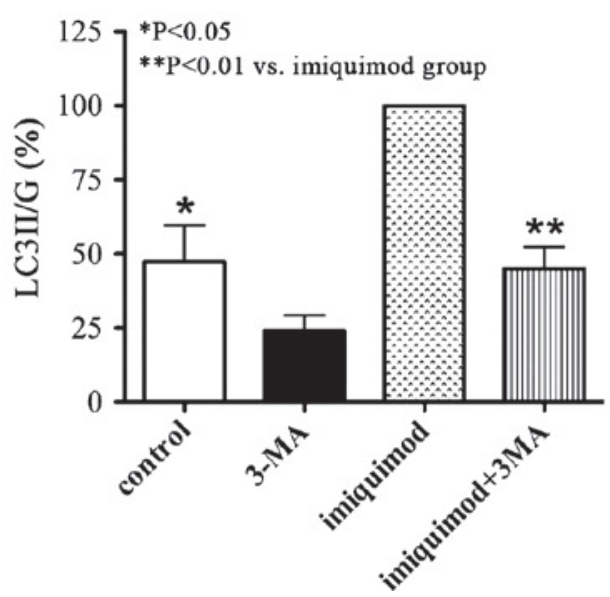

Figure 2. Imiquimod induces autophagy in SGC-7901 cells. (A) Cells were stained with monodansylcadaverine after treatment with $100 \mu \mathrm{g} / \mathrm{ml}$ imiquimod. (B) Electron microscopy of SGC-7901 cells. (a) Control cells. (b) Cells were incubated with $100 \mu \mathrm{g} / \mathrm{ml}$ imiquimod for $12 \mathrm{~h}$ (scale bar, $2 \mu \mathrm{m}$ ). Magnified windows from b show (c) an autolysosome (Avd) and (d) autophagosomes (Avi) (arrows). (C) Cells were treated with various doses of imiquimod for $24 \mathrm{~h}$ and the expression levels of LC3I, LC3II and Beclin1 were determined by western blot analysis. (D) Cells were treated with $100 \mu \mathrm{g} / \mathrm{ml}$ imiquimod for 6-24 h and changes in LC3I, LC3II and Beclin1 were detected by western blot analysis. (E) Cells were treated with $100 \mu \mathrm{g} / \mathrm{ml}$ imiquimod in the presence or absence of 3-MA for $24 \mathrm{~h}$. Changes in LC3I and LC3II were detected by western blot analysis. (F) Quantified levels of LC3II from E normalized to GAPDH. Values are expressed as the mean \pm standard deviation $(\mathrm{n}=3)$. ${ }^{* *} \mathrm{P}<0.01$, vs. control; " $\mathrm{P}<0.05$, vs. imiquimod-treated cells. MA, methyladenine; LC, light chain.

cat no. sc-2048; Santa Cruz Biotechnology, Dallas, TX, USA) in accordance with the manufacturer's instructions. Images of blots were captured using a Chemiluminescence Imaging System (CoreBio, Seoul, Republic of Korea).

Flow cytometry. SGC-7901 cells were seeded in six-well plates at $1 \times 10^{5}$ cells/well and following $1 \mathrm{~h}$ of pre-incubation with $5 \mathrm{mM} 3$-MA, cells were treated with imiquimod $(100 \mu \mathrm{g} / \mathrm{ml})$ for $24 \mathrm{~h}$. Cells were harvested, washed twice with pre-cooled PBS and centrifuged at 20,627 x g for $10 \mathrm{~min}$. Cells were then re-suspended in $500 \mu \mathrm{l}$ binding buffer, and incubated in $5 \mu \mathrm{l}$ annexin V-fluorescein isothiocyanate (FITC) and $10 \mu \mathrm{l}$ propidium iodide (PI) included in a Annexin V-FITC Apoptosis 81 kit (cat no. K101-100; BioVision, Milpitas, CA, USA) at room temperature in the dark for $15 \mathrm{~min}$. Staining was then quantified using flow cytometry (Beckman Coulter, Brea, CA, USA) within $1 \mathrm{~h}$.

Statistical analysis. All experiments were repeated at least three times, and value are expressed as the mean \pm standard deviation. Data were analyzed using Student's two-tailed t-test or analysis of variance using SPSS 16.0 statistical software (SPSS, Inc., 
Chicago, IL, USA) to determine the significance of differences between groups. $\mathrm{P}<0.01$ was considered to indicate a statistically significant difference between values.

\section{Results}

Anti-proliferative effects of imiquimod. As shown in Fig. 1A, imiquimod inhibited the proliferation of SGC-7901 cells in a dose- and time-dependent manner. The $\mathrm{IC}_{50}$ value of imiquimod at $24 \mathrm{~h}$ was $71.13 \pm 7.81 \mu \mathrm{g} / \mathrm{ml}$. While effects of low doses of imiquimod ( 25 and $50 \mathrm{Mg} / \mathrm{ml}$ ) on the cell viability were obvious at as early as $12 \mathrm{~h}$ of treatment, high doses of imiquimod (100 and $200 \mu \mathrm{g} / \mathrm{ml}$ ) led to a $>25 \%$ reduction in cell viability at 48 and $72 \mathrm{~h}$ of treatment. Following treatment of SGC-7901 cells with the selective autophagy inhibitor 3-MA $(5 \mathrm{mM})$, the viability of SGC-7901 cells was reduced compared with that of control cells; furthermore, pre-treatment with $5 \mu \mathrm{M}$ of 3-MA significantly attenuated the growth-inhibitory effects of imiquimod (100 $\mu \mathrm{g} / \mathrm{ml})$ (Fig. 1B).

Imiquimod increases the occurrence of autophagy in gastric cancer cells. To test the autophagic activity induced by imiquimod, MDC staining was performed fist. As shown in Fig. 2A, the control cells showed faint fluorescence, while the SGC-7901 cells treated with $100 \mu \mathrm{g} / \mathrm{ml}$ imiquimod accumulated MDC into granular structures of high fluorescence intensity. Furthermore, transmission electron microscopic analysis was performed to examine the formation of autophagic vesicles. Compared with the untreated cells, an abundance of autophagosome-like vacuoles containing double-membrane structures were identified in the cytoplasm of $100 \mu \mathrm{g} / \mathrm{ml}$ imiquimod-treated SGC-7901 cells following $12 \mathrm{~h}$ of incubation (Fig. 2B).

Imiquimod enhances the expression of autophagy-associated proteins. The levels of LC3II, which is considered the hallmark of mammalian autophagy (14), as well as the expression of autophagy-associated protein Beclin1 were examined by western blot analysis. After treatment of SGC-7901 cells with various concentrations of imiquimod for $24 \mathrm{~h}$, a marked and concentration-dependent upregulation of LC3II expression and an increase in the LC3II/LC3I ratio were observed compared with the untreated control cells. Furthermore, imiquimod increased Beclin1 levels in a time-dependent manner (Fig. 2C). The induction of LC3II and Beclin1 expression was observed at as early as $6 \mathrm{~h}$ of treatment with imiquimod (Fig. 2D). Furthermore, the increase of LC3II expression was blocked in the presence of the autophagy inhibitor 3-MA (Fig. 2E).

Apoptosis is induced by imiquimod. To confirm that imiquimod was able to induce apoptosis in SGC-7901 cells, the present study assessed the expression of apoptotic signaling proteins by western blot analysis. After treatment with $100 \mu \mathrm{g} / \mathrm{ml}$ imiquimod, a substantial decrease in the expression of Bcl-2 and increased cleavage of caspase-3, caspase- 9 and Bax was observed at 24 and $36 \mathrm{~h}$ of treatment with imiquimod (Fig. 3A). Next, the present study assessed whether imiquimod- induced autophagy has a protective or an apoptosis-promoting effect on SGC-7901 cells. For this purpose, the apoptotic rate was assessed by flow cytometry following Annexin V-FITC/PI staining. As shown in Fig. 3B,
$\mathbf{A}$

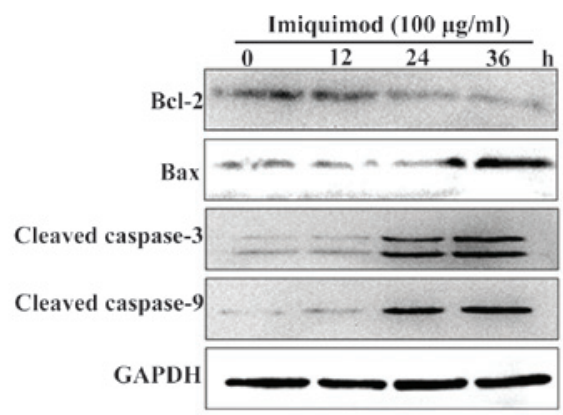

B
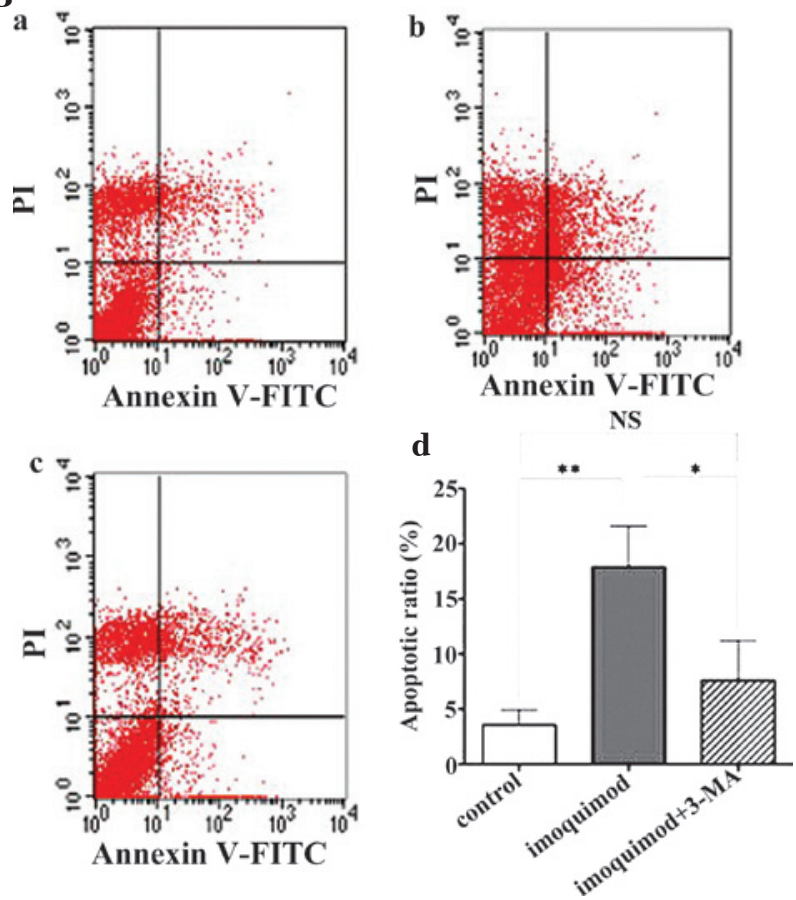

Figure 3. Imiquimod induces apoptosis in SGC-7901 cells. (A) Cells were treated with $100 \mu \mathrm{g} / \mathrm{ml}$ imiquimod for $0-36 \mathrm{~h}$ and the expression levels of Bcl-2, cleaved caspase-3/-9 and Bax were determined by western blot analysis with GAPDH as a loading control. (B) Apoptotic rates of SGC-7901 cells treated with $100 \mu \mathrm{g} / \mathrm{ml}$ imiquimod for $24 \mathrm{~h}$ with or without 3-MA were determined by Annexin V/PI staining and flow cytometric analysis. (a) Control cells; (b) $100 \mu \mathrm{g} / \mathrm{ml}$ imiquimod-treated cells; (c) cells treated with $100 \mu \mathrm{g} / \mathrm{ml}$ imiquimod and 3-MA; (d) the apoptotic rates were quantified by calculating the percentage of Annexin V+/PI- cells. Values are expressed as the mean \pm standard deviation. ${ }^{* *} \mathrm{P}<0.01$, vs. control; ${ }^{*} \mathrm{P}<0.05$, vs. imiquimod-treated cells. MA, methyladenine; Bcl-2, B-cell lymphoma 2; Bax, Bcl-2-associated X protein; FITC fluorescein isothiocyanate; PI, propidium iodide; NS, not significant.

the number of apoptotic cells was enhanced following $24 \mathrm{~h}$ of treatment with $100 \mu \mathrm{g} / \mathrm{ml}$ imiquimod, which was, however, significantly decreased by pre-treatment with 5 mM 3-MA. This result indicated that imiquimod-induced apoptosis of SGC-7901 cells proceeded, at least in part, via an autophagic process, and that autophagy had a pro-apoptotic function.

\section{Discussion}

Imiquimod, the most commonly used TLR7 agonist, has been approved by the United States Food and Drug Administration as the first-line topical treatment for basal cell carcinoma (15). In addition, an increasing number of studies have clearly demonstrated that imiquimod shows anti-proliferative effects in a variety of benign and malignant carcinomas, including 
colorectal (5), prostate (16), bladder (17), renal (18) and oral cancer (19). However, whether imiquimod is able to decrease the viability of gastric cancer cells as well as its mechanisms of action have remained elusive.

In the present study, an MTT assay showed that imiquimod markedly decreased the viability and proliferation of SGC-7901 cells in a dose- and time-dependent manner. Treatment with $100 \mu \mathrm{g} / \mathrm{ml}$ imiquimod started to inhibit cell viability at an early time-point ( $12 \mathrm{~h}$ ), while cell viability was reduced to $>25 \%$ at $36 \mathrm{~h}$. A previous study by our group (20) indicated that incubation with $100 \mu \mathrm{g} / \mathrm{ml}$ imiquimod for $24 \mathrm{~h}$ resulted in SGC-7901-cell apoptosis as demonstrated by an increased ratio of early apoptotic cells and marked ultrastructural changes in the cells, while this phenomenon was not observed at $12 \mathrm{~h}$. In order to prove that imiquimod induces apoptosis in gastric cancer cells, the present study assessed the expression of a number of apoptotic proteins. Activation of cleaved caspase-3 and -9 indicated that imiquimod-induced apoptosis may proceed via the caspase-dependent pathway. A significant change in the levels of apoptosis-associated proteins was observed at 24 and $36 \mathrm{~h}$ of treatment with imiquimod, while autophagy-associated proteins were enhanced at as early as $8 \mathrm{~h}$. Therefore, present study aimed to further investigate the mechanism by which imiquimod induced cell death in gastric cancer cells; in particular, the early effects of imiquimod treatment leading to cell death and the implication of autophagy were investigated.

Autophagy, classified as type II programmed cell death, is a mechanism which can be clearly distinguished from apoptosis. Autophagy was originally described as a mechanism to maintain homeostasis through the depredation of long-lived proteins and damaged organelles (21). It is usually induced as a mechanism of stress tolerance when cells are exposed to starvation, hypoxia, reactive oxygen species or anti-tumor treatment. It has been suggested that dysregulation of autophagy has a vital role in gastric tumorigenesis (22). Previous studies also indicated that imiquimod exerts a direct autophagic effect through the activation of autophagy-associated molecules to promote cell death in certain tumor types $(5,7)$. The present study demonstrated that the rate of autophagy was significantly higher in imiquimod-treated cells compared with that in the untreated controls, as evidenced by the obvious increase in autophagic markers, including autophagosome formation and positivity for MDC staining. Treatment with imiquimod also dose-dependently induced the upregulation of autophagy makers LC3II and Beclin1. 3-MA, an inhibitor of autophagy, was observed to decrease the toxicity of imiquimod, while it did not completely prevent cell death. The apoptotic rate was increased following treatment with $100 \mu \mathrm{g} / \mathrm{ml}$ imiquimod for $24 \mathrm{~h}$, while it was significantly decreased by pre-treatment with 3-MA. These results indicated that in SGC-7901 cells, autophagy is a cell death mechanism activated by imiquimod, and that blocking of autophagy with 3-MA inhibited the activation of apoptosis.

In conclusion, to the best of our knowledge, the present study was the first to demonstrate that imiquimod exhibited efficacy against gastric cancer cells in vitro. The results indicated that imiquimod induced autophagy as well as apoptosis, which led to the death of SGC-7901 cells; furthermore, early induction of autophagy by imiquimod may trigger apoptosis. Based on these findings, it is concluded that imiquimod may be a potential anti-tumor agent for the treatment of gastric cancer.

\section{Acknowledgements}

The present study was supported by the Fundamental Research Funds for the Central Universities (National twelfth five-year plan of science and technology; grant no. 2012BAJ18B03-03).

\section{References}

1. Akira S and Takeda K: Toll-like receptor signalling. Nat Rev Immunol 4: 499-511, 2004.

2. Suzuki N, Suzuki S and Yeh WC: IRAK-4 as the central TIR signaling mediator in innate immunity. Trends. Immunol 23: 503-506, 2002.

3. Tse K and Horner AA: Update on toll-like receptor-directed therapies for human disease. Ann Rheum 66 (Suppl 3): iii77-iii80, 2007.

4. Miller RL, Gerster JF, Owens ML, Slade HB and Tomai MA: Imiquimod applied topically: A novel immune response modifier and new class of drug. Int J Immunopharmacol 21: 1-14, 1999.

5. Yi JY, Jung YJ, Choi SS, Hwang J and Chung E: Autophagy-mediated anti-tumoral activity of imiquimod in Caco-2 cells. Biochem Biophys Res Commun 386: 455-458, 2009.

6. Schön MP, Wienrich BG, Drewniok C, Bong AB, Eberle J, Geilen CC, Gollnick H and Schön M: Death receptor-independent apoptosis in malignant melanoma induced by the small-molecule immune response modifier imiquimod. J Invest Dermatol 122: 1266-1276, 2004.

7. Huang SW, Liu KT, Chang CC, Chen YJ, Wu CY, Tsai JJ, Lu WC, Wang YT, Liu CM and Shieh JJ: Imiquimod simultaneously induces autophagy and apoptosis in human basal cell carcinoma cells. Br J Dermatol 163: 310-320, 2010.

8. Rubinsztein DC, Gestwicki JE, Murphy LO and Klionsky DJ: Potential therapeutic applications of autophagy. Nat Rev Drug Discov 6: 304-312, 2007.

9. Schönthal AH: Endoplasmic reticulum stress and autophagy as targets for cancer therapy. Cancer Lett 275: 163-169, 2009.

10. Gozuacik D and Kimchi A: Autophagy as a cell death and tumor suppressor mechanism. Oncogene 23: 2891-2906, 2004.

11. Mathew R, Karantza-Wadsworth V and White E: Role of autophagy in cancer. Nat Rev Cancer 7: 961-967, 2007.

12. Crew KD and Neugut AI: Epidemiology of gastric cancer. World J Gastroenterol 12: 354-362, 2006.

13. Ferlay J, Shin HR, Bray F, Forman D, Mathers C and Parkin DM: Estimates of worldwide burden of cancer in 2008: GLOBOCAN 2008. IntJ Cancer 127: 2893-2917, 2010.

14. Mizushima N and Yoshimori T: How to interpret LC3 immunoblotting. Autophagy 3: 542-545, 2007.

15. Tyring S, Conant M, Marini M, Van Der Meijden W and Washenik K: Imiquimod; an international update on therapeutic uses in dermatology. Int J Dermatol 41: 810-816, 2002.

16. Han JH, Lee J, Jeon SJ, Choi ES, Cho SD, Kim BY, Kim DJ, Park JH and Park JH: In vitro and in vivo growth inhibition of prostate cancer by the small molecule imiquimod. Int J Oncol 42: 2087-2093, 2013.

17. Smith EB, Schwartz M, Kawamoto H, You X, Hwang D, Liu H and Scherr DS: Antitumor effects of imidazoquinolines in urothelial cell carcinoma of the bladder. J Urol 177: 2347-2351, 2007.

18. Schwartz MJ, Liu H, Hwang DH, Kawamoto H and Scherr DS: Antitumor effects of an imidazoquinoline in renal cell carcinoma. Urology 73: 1156-1162, 2009.

19. Ahn MY, Kwon SM, Cheong HH, Park JH, Lee J, Min SK, Ahn SG and Yoon JH: Toll-like receptor 7 agonist, imiquimod, inhibits oral squamous carcinoma cells through apoptosis and necrosis. J Oral Pathol Med 41: 540-546, 2012.

20. Jiang J, Dong L, Qin B, Guo X, Li H, Shi H and Liu Y: Expression of Toll-like receptor 7 (TLR7) in gastric cancer cell lines and effects of TLR7 agonist on proliferation and apoptosis of SGC-7901 cells in vitro. J South Med Univ 34: 1606-1610, 2014 (In Chinese).

21. Mizushima N, Levine B, Cuervo AM and Klionsky DJ: Autophagy fights disease through cellular self-digestion. Nature 451: 1069-1075, 2008.

22. Liu D, Gao M and Zhao S. Autophagy as a novel strategy for treatment of gastric cancer: A hypothesis. Med Sci Monit 19: 794-796, 2013. 